\title{
Una revista para conocernos y reconocernos
}

La Asociación Lacinoamericana de Estudios del Discurso (AltL) nació en febrero de 1995, durante las deliberaciones del I Coloquio Latinoamericano de Estudios del Discurso, celebrado en Caracas, coordinado por Adriana Bolívar y auspiciado por la Coordinación de Estudios de Postgrado de la Universidad Central de Venezuela. Al amparo de ese evento inicial para el que un comité optó por la aceptación de ochenta y seis ponencias provenientes principalmente de seis países de América Latina (Argentina, Brasil. Colombia, Chile, México y Venezuela), surgía esta Asociación profesional con el propósito de abrir un espacio académico en el que tuvieran cabida los distintos proyecros de Análisis del Discurso que desde hacía ya varios años se estaban desarrollando en todo el concinenre. Si bien los estudiosos de la teoría y aplicaciones de la Lingüistica del Texto estaban inregrados a otras instituciones que, periódica y exitosamente, habían consolidado para ese momento sus evencos particulares (la ALFAL, por ejemplo), ya desde comienzos de la década de los novenca se habia vislumbrado la necesidad de una organización que fuera específica de los escudios discursivos, a fin de que desde ella pudiera motorizarse y orientarse toda la investigación que se habia venido haciendo de modo disperso desde cada uno de los países latinoamericanos. Y precisamence, el estímulo, la solidaridad profesional y el establecimiento de una normativa específica para las investigaciones del y sobre el discurso, son ya una realidad mucho más que patente en el ámbito de la linguística latinoamericana.

Aquel primer coloquio anda ya por su cuarta versión (la última de ellas hasta hoy realizada en sepriembre de 2001, en Recife. Brasil, auspiciado por la Universidad Federal de Pernambuco, y coordinado por Luiz Antônio Marcuschi), evento que se suma a las muy exitosas realizaciones previas de La Plara-Buenos Aires (II Coloquio, agosto de 1997, coordinado por Luisa Granato) y Santiago de Chile (III Coloquio, abril de 1999, coordinado por Leda Berardi). Actividad internacional a la que habría que sumar los coloquios nacionales de análisis (o analistas) del discurso que han venido realizándose en cada uno de los países en los que la ALED cuenta con delegaciones regionales, y cuyo resumen ofrecemos en el cuadro siguiente: 


\begin{tabular}{|c|c|c|}
\hline PAIS E INSTITUCION & LUGAR Y FECHA & COORIJINAI)XR(ES) \\
\hline $\begin{array}{c}\text { Colombia, Universidad } \\
\text { del Valle }\end{array}$ & Cali, mayo. 1996 & $\begin{array}{l}\text { Maria C. Marrínc\% y } \\
\text { Eduardo Serrano O. }\end{array}$ \\
\hline $\begin{array}{l}\text { Argentina, Universidad } \\
\text { de Buenos Aires y } \\
\text { Universidad de La Plata }\end{array}$ & $\begin{array}{l}\text { Buenos Aires. } \\
\text { junio, } 1996\end{array}$ & Luisa Ciranato \\
\hline $\begin{array}{c}\text { Venezuela, Universidad } \\
\text { Simón Bolívar }\end{array}$ & Caracas, junio. 1996 & Luis Barrera Linares \\
\hline $\begin{array}{c}\text { Chile, Universidad de } \\
\text { Chile }\end{array}$ & Santiago, enero, 1997 & $\begin{array}{c}\text { Leda Berardi y Silvia } \\
\text { Icurreca T. }\end{array}$ \\
\hline $\begin{array}{c}\text { Venezuela, Universidad } \\
\text { de los Andes }\end{array}$ & Mérida, junio, 1998 & $\begin{array}{c}\text { Luurdes Pietroscmoli. } \\
\text { Luis Barrera Linares y } \\
\text { Alexandra Alvarez }\end{array}$ \\
\hline $\begin{array}{l}\text { Colombia, Universidad } \\
\text { del Atlántico y Círculo } \\
\text { de Análisis del Discurso. }\end{array}$ & $\begin{array}{l}\text { Barranquilla, } \\
\text { diciembre, } 1999\end{array}$ & $\begin{array}{c}\text { Julio Escamilla, Luz M. } \\
\text { Torres, Efrain Morales y } \\
\text { Grandfield Henry }\end{array}$ \\
\hline $\begin{array}{c}\text { Venezuela. Universidad } \\
\text { Experimental Francisco } \\
\text { de Miranda }\end{array}$ & Coro. septiembre, 2000 & $\begin{array}{l}\text { Mirian García y } \\
\text { Tercsa Espar }\end{array}$ \\
\hline $\begin{array}{l}\text { México. Universidad } \\
\text { Auronoma Metroplitana }\end{array}$ & $\begin{array}{l}\text { Ciudad de México, } \\
\text { Junio, } 2001\end{array}$ & Irene Fones \\
\hline $\begin{array}{c}\text { Argentina, Universidad } \\
\text { Nacional de La Plata }\end{array}$ & $\begin{array}{c}\text { La Plata, } \\
\text { septiembre, } 2001\end{array}$ & Gladys Lopreto \\
\hline
\end{tabular}

Es obvia entonces la importancia que en los diferentes paises ha ejercido la acrividad de quienes se han desempeñado como delegados regionales y la responsabilidad investigativa de cada uno de los socios de la AIF.D, situación que se manifiesta en la variedad de ponencias discucidas en cada ocasión.

Y ante tal panorama, la AlED ha asumido el compromiso de propiciar el logro de otro de los objetivos trazados desde aquella reunión inicial de Caracas. El mismo se relaciona con la necesidad de un órgano institucional que sirva de medio divulgativo, no sólo para reflejar las distintas orientaciones de la investigación y el análisis del discurso, sino también para fortalecer por la vía de la difusión de trabajos y reseñas los vínculos entre los distintos mıembros. Ese objetivo comienza a hacerse realidad con la edición de esre primer número de la revisca de la ALFD. Por supuesco que hemos aspirado a una publicación periódica que se aluste a todos los requermientos de rigor científico. metodológico y formal exigidos por la actual invesugación en Ciencias Sociales. Así, la necesidad de nacer con un primer número nos impuso la decisión de una solicitud abierta de artículos y reseñas que pudieran ser sometidos al dictamen de una serie de árbitros escogidos entre los mismos socios 
de la ALED. Sin embargo, ante la muy poca recepción de artículos, tuvimos que acudir directamente a algunos autores en particular para que nos ofrecieran algún texto que pudiera ser incluido en este número inicial. Esta doble metodología ha incidido tanto en la forma de organización como en las maneras particulares de presentar los artículos y las reseñas. No obstante, hemos de señalar que dicha situación se formalizará defanitivamente a partir del segundo número. Primero, porque esperamos que la revista se constituya en un verdadero órgano de divulgación de la actividad investigativa que se realiza en los distintos países. Segundo, porque insistiremos en el derecho que asiste a todos y cada uno de los socios para someter sus artículos ante los edicores, quienes a su vez estarán obligados a decidir la publicación de los mismos a partir de los dictámenes ciegos de quienes en cada caso se constituyan como comité de arbitraje (que igualmente deberá incluir investigadores de los distintos países y de diversas orientaciones teóricas y metodológicas). Tercero. porque para efecto de los requerimientos formales de los próximos números, se ha incluido aqul una normativa muy específica a la que deberán atenerse quienes de ahora en adelante deseen someter (o sean invitados a presentar) sus artículos y reseñas para la posibilidad de publicación en futuros volúmenes. De manera que cualquier socio solvente ante su delegación regional tendrá el derecho de enviar sus artículos a fin de que sean evaluados como porenciales publicaciones. $\mathrm{Y}$ los invitamos a hacerlo.

Por orra parte, esperamos que este número inicial, deje muy clara la orientación de la revista: apertura hacia las distintas tendencias teóricas y merodológicas de los estudios del discurso en Lacinoamérica y amplitud que evidencie la multiplicidad geográfica $e$ investigativa de lo que ha sido y sigue siendo la ALED. Eso es precisamente lo que nos lleva a ofrecer en esta primera enrrega articulos que van desde el desarrollo y sistematización de propuestas teóricas sobre el contexto y los distintos cipos de comperencia (Teun van Dijk, Patrick Charaudeau) hasta aquellos que se aproximan a asuntos de carácter interactivo y metodológico (Luiz Antônio Marcuschi y Teresa Carbó), o que, a partir de una teoría particular, se adentran en el análisis de algún texto específico (Teresa Espar). Un agradecimiento muy especial para Teun van Dijk, nuestro primer socio honorario, por ofrecernos la posibilidad de publicar su primer texto escrito en español por él mismo. Igualmente, una palabra de gratitud para Patrick Charaudeau por la diligencia y gencileza en el envío de su rexro y en la revisión de la traducción al español, realizada por el profesor Jean Louis Rebillou (de la Universidad Central de Venezuela), a quien también debernos el debido reconocimiento. Imposible obviar la colaboración incalculable de Martha Shiro, a cargo de la sección de reseñas, y la de Lenita Vieira, quien gentil y desinteresadamente contribuyó con la traducción de los resúmenes al portugués.

Ante la evidencia de que ya la revista, más que un proyecro, es una realjdad, esperamos contar a partir de este momento con la voluntad y el deseo 
de los socios para proponer sus artículos. $Y$ en esto será fundamental la cooperación y difusión que de este propósito hagan de nuevo los delegados regionales en cada país.

Con este número queda entonces saldada la primera y muy elemental etapa de lo que fue orro de los objetivos fundamentales al propiciar la fundación de la ALED. No seremos, obviamente, la única publicación dedicada exclusivamente a los estudios del discurso, pero hemos surgido para compartir preocupaciones y propósitos con las publicaciones que nos han precedido y con las que surian más adelante. Abrigamos la esperanza de contribuir a estrechar los vínculos que nos ayuden a conocernos y reconocernos entre nosotros $y$ a esrablecer los necesarios nexos con investigadores de otros espacios (Europa, Norteamérica, otros continentes). Muchos son los factores geopolíricos, sociales. educativos y económicos que aquejan el espacio latinoamericano. $Y$ nadie tiene dudas sobre el modo como estas situaciones se asientan, se consolidan y se legitiman a través de las varianres discursivas. Tenemos asi la inmensa tarea de contribuir para conocernos y comunicarnos con la fluidez que exigen un tiempo y una tecnología tan cambiantes como complejos. La revista de la ALtD será de esa manera una posibilidad más para que intercambiemos entre nosotros y con pares y colegas de orros espacios lo que hacemos en materia de análisis del discurso y para contribuir a que otros adquieran conciencia del papel primordial que el lenguaje desempeña en la actividad del ser humano. $\mathrm{H}_{\text {a }}$ surgido para propiciar y estimular los escudios del discurso en una región del mundo que tiene sus problemas propios y que debe investigarlos para conocerlos y contribuir de algun modo en su solución. 